\title{
Mutual Coupling Reduction in Patch Antenna Array Based on EBG Structure for MIMO Applications
}

\author{
Yahiea Alnaiemy ${ }^{1,2 *}$, Taha A. Elwi ${ }^{3}$ Lajos Nagy ${ }^{1}$ \\ 1 Department of Broadband Infocommunications and Electromagnetic Theory, Faculty of Electrical Engineering and Informatics, \\ Budapest University of Technology and Economics, H-1521 Budapest, P.O.B. 91, Hungary \\ 2 Department of Computer Science, College of Science, University of Diyala, 32014 Khan Bani Sa`Ad, post code 2, Diyala, Iraq \\ ${ }^{3}$ Department of Communication Engineering, Al-Ma'mun University College, 14th Ramadan Street, Al-Mansur, Baghdad, Iraq \\ * Corresponding author, e-mail: yahiea@hvt.bme.hu
}

Received: 14 May 2019, Accepted: 06 August 2019, Published online: 10 October 2019

\begin{abstract}
This paper presents a printed rectangular slot microstrip antenna array of two elements based on an Electromagnetic Band Gap (EBG) structure. The proposed EBG structure is invented to improve the isolation between the radiating elements for multiple-input multiple-output (MIMO) application. Single and two slotted rectangular microstrip antennas are designed on an FR-4 substrate with a dielectric constant $\left(\varepsilon_{r}\right)$ of 4.3 and loss tangent $(\tan \delta)$ of 0.025 with thickness of $1.6 \mathrm{~mm}$. The proposed EBG structure is designed as one planar row of 24 slots. The proposed array performance is tested numerically using Computer Simulation Technology Microwave Studio (CSTMW) of Finite Integration Technique (FIT) formulations. The antenna performance in terms of reflection coefficient $\left(S_{11}\right)$, isolation coefficient $\left(S_{21}\right)$, radiation patterns, boresight gain and Envelope Correlation Coefficient (ECC) are investigated before and after introducing the EBG structure to identify the significant enhancements. The proposed EBG structure is located between the radiating antenna elements to reduce the mutual coupling of the proposed antenna array. The edge to edge separation distance of the proposed antennas is $\lambda_{0} / 16$, where the $\lambda_{0}$ is the free space wavelength at $2.45 \mathrm{GHz}$. The simulated results show a significant isolation enhancement from $-6 \mathrm{~dB}$ to $-29 \mathrm{~dB}$ at the first resonant frequency $2.45 \mathrm{GHz}$ and from $-10 \mathrm{~dB}$ to $-25 \mathrm{~dB}$ at the second resonant frequency $5.8 \mathrm{GHz}$ after introducing the EBG structure to the antenna array.
\end{abstract}

Keywords

antenna array, EBG, mutual coupling, MIMO

\section{Introduction}

Due to the rapid developments in mobile communication technologies in our daily life [1], printed radio frequency circuits based on compacted metamaterials have received a considerable attraction by several researcher communities [2]. Therefore, several eager attempts from researches have conducted to investigate the use of different antennas based on different types of metamaterials to improve the antenna performance in term of bandwidth [3], gain [4], radiation pattern [5], and mutual coupling reduction [6]. For instance, the EBG structure was invoked to enhance the microstrip antenna performance to miniaturize the size [7], improve the gain [8], and the radiation patterns [9]. Furthermore, EBG structures were utilized based on different approaches such as defecting ground planes, etched metallic structures, and periodical apertures in dielectric substrates. Yablonovitch [1] and John [2] were the first who

investigated the EBG structures conceptions. In [3], four modified Split Ring Resonator (SRR), Capacitive Loaded Strip (CLS) and wire structures were applied with the proposed antenna to enhance the antenna bandwidth and miniaturize the antenna size. Several attempts from the researchers were reported in [4-6] to explore mutual coupling reduction between the radiating antenna elements, and improving antennas performances such as bandwidth, gain, and radiation efficiency and size reduction. A Frequency Selective Surface (FSS) was developed for a folded antenna based on EBG structure for breast cancer detection was reported in [4]. The author in [5] explored a miniaturized EBG structure based on ground plane defect for MIMO systems. Furthermore, a Bended Complementary SRR (BC-SRR) was realized to reduce the mutual coupling effect based on folded MIMO antenna in [6]. 
Mutual coupling is one of the major drawbacks with antenna array design. Therefore, an attempt is applied to tackle the undesirable effects by the researchers in [7]. Introducing EBG structure between the antenna elements has the ability to suppress the surface wave propagation in interested frequency bands [8].

Recently, several researchers have been investigating enhancement the performance of microstrip antennas by introduction of metamaterials and EBG structures [9-11]. For example EBG structure was applied above the antenna patch to enhance the antenna boresight gain [9]. In [10] the authors applied E-plane meander line uniplanar compact EBG (UC-EBG) and H-plane meander line UC-EBG between the radiating elements for mutual coupling reduction of MIMO applications. The authors in [11] suggested the introduction of $2 \times 5$ EBG structure between two rectangular patch antenna arrays to reduce the mutual coupling between the array elements. Employing rectangular patch in between the two monopole antennas to reduce the mutual coupling was introduced in [12]. A periodic array of mushroom like EBG structure is implemented with microstrip antennas was reported in [13] to achieve mutual coupling reduction. To reduce the surface wave excitation in printed rectangular patch antenna the authors in [14] investigated mushroom like EBG structure to mitigate the mutual coupling between the radiating antenna elements. A suspended metasurface composed periodic square SRR was applied above the antenna array in [15] for mutual coupling reduction, the proposed metasurface has the ability to reject the unwanted radiation as well as reducing mutual coupling in array antenna. An UC-EBG structure was introduced on the top of the antenna layer for mutual coupling reduction and antenna array miniaturization was reported in [16]. The authors in [17] integrated 3D metamaterial (3D MTM) structure in to MIMO antenna to improve the mutual coupling reduction between the radiating antenna elements. Finally, for the frequency beam scanning the authors in [18] are using metamaterial decoupling slab (MTM DS) to suppress mutual coupling encountered in antenna arrays, which is needed in MIMO and synthetic aperture radars systems.

This paper gives a comprehensive study to design a microstrip antenna array of two slotted radiating patch elements based EBG structure to improve the mutual coupling reduction for MIMO applications. Numerical simulation tools based on Finite Integration Technique (FIT) of CST MWS formulation [19] is involved to investigate the performance of the proposed array. A comparison between the proposed array performance with and without EBG structure is investigated to realize the differences. The optimal antenna array dimensions, the number of EBG unit cells, and separation distance between the antenna elements are discussed. Furthermore, another investigation is accomplished on the proposed antenna when folded on cylindrical substrate to suit highly compacted MIMO systems. Therefore, a comparison study is summarized between the conventional planar antenna arrays and folded profiles. This paper is organized as following: in Section 2, the geometry of the proposed antenna array and EBG structure are introduced. A parametric study of designing a single element and antenna array are presented in this section also. The performance of the antenna array before and after EBG structure based on folded antenna array is presented in Section 3. Envelope Correlation Coefficient is presented in Section 4. We conclude the paper in Section 5.

\section{Antenna geometry}

In this Section, a systematic design methodology is invoked to optimize the proposed antenna array performance in term of reflection coefficient $\left|S_{11}\right|$, mutual coupling reduction, boresight gain, and radiation pattern is explored in details. Our study is divided into two main parts: The first part is focusing on the patch geometry design and the second part is discussing the antenna array design with and without EBG structure. The influence of the separation distance between the radiating antenna elements on their performance has been reported in this part. As far as the bending of antenna array in MIMO system is concerned, the authors investigated the bending effect of the antenna array elements performances. The proposed antenna is designed for dual band at $2.45 \mathrm{GHz}$, and $5.8 \mathrm{GHz}$ for WLAN and Wi-Fi communication systems.

\subsection{Single antenna element}

The systematic design methodology is optimized the proposed antenna performance in term of reflection coefficient $\left|S_{11}\right|$ and boresight gain. In the parametric study, changing the antenna dimensions is conducted to verify the optimal antenna geometry to suit the WLAN and Wi-Fi bands. The patch antenna element is mounted on a low cost FR-4 substrate with dimensions of $50 \times 50 \mathrm{~mm}^{2}$ with a thickness of $1.6 \mathrm{~mm}$ and relative permittivity $\left(\varepsilon_{r}\right)$ of 4.3 and a loss tangent $(\tan \delta)$ of 0.025 . The patch is fed by a $50 \Omega$ microstrip transmission line of $3 \mathrm{~mm}$ in width and positioned on the substrate and backed by a partial ground plane as depicted in Fig. 1. The geometrical details are presented in Fig. 1 and listed in Table 1. 
(a)

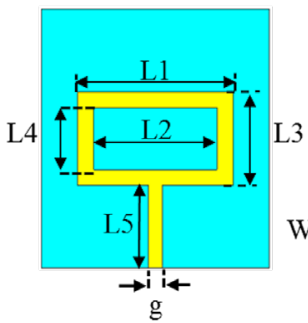

(b)

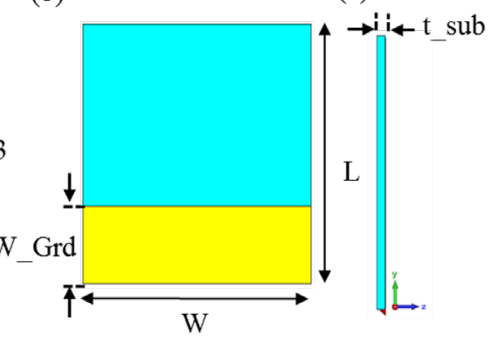

Fig. 1 Geometry of the proposed patch antenna structure; (a) front view, (b) back view, and (c) side view

Table 1 The geometric dimensions of the proposed patch antenna

\begin{tabular}{lccc}
\hline Parameter & Dimension & Parameter & Dimension $(\mathrm{mm})$ \\
\hline$W$ & 50 & $L 3$ & 18 \\
$L$ & 50 & $L 4$ & 12 \\
$W \_$Grd & 15 & $L 5$ & 16 \\
$L 1$ & 34 & $g$ & 3 \\
$L 2$ & 27 & $t \_s u b$ & 1.6 \\
\hline
\end{tabular}

The authors provide a systematic design procedure using a numerical simulation based on CSTMWS formulations to achieve the final antenna design. The design is started with a rectangular patch backed with a full ground plane. Next, a rectangular slot is etched from the patch as seen in Fig. 2. The slotted patch boundary width is considered $(m)$ is changed from $1 \mathrm{~mm}$ to $5 \mathrm{~mm}$.

It is found when $m$ is $3 \mathrm{~mm}$, a resonance frequency at $2.45 \mathrm{GHz}$ is appeared but with poor impedance matching. Therefore, the authors are decided to consider the value $m=3 \mathrm{~mm}$ is the best choice; however, it may need to enhance the antenna matching at this frequency band.

Next, the influence of changing the ground plane width given by $\left(W_{-} G r d\right)$ is investigated. In this study, we started with a full ground plane antenna and compare the performance of the antenna with a partial ground plane as seen in Fig 3. Based on impedance matching results and the antenna gain at $2.45 \mathrm{GHz}$ and $5.8 \mathrm{GHz}$, it is proven that the antenna with the partial ground plane has better performance than the antenna design with full ground plane. Such enhancement could be attributed to the reduction in the surface wave, skew waves, and motions on the ground plane surface [5]. Therefore, the authors changed the $W_{-} G r d$ from $12 \mathrm{~mm}$ up to $21 \mathrm{~mm}$ step by $3 \mathrm{~mm}$. Fig. 3 shows that by increasing $W_{-} G r d$, the frequencies are shifted to lower bands with an observable degradation in impedance matching as indicated in Fig. 3(a). Therefore, the optimal case in term of the frequency resonance and impedance matching is found at $W_{-} G r d=15 \mathrm{~mm}$ that the requirements of WLAN and Wi-Fi bands.

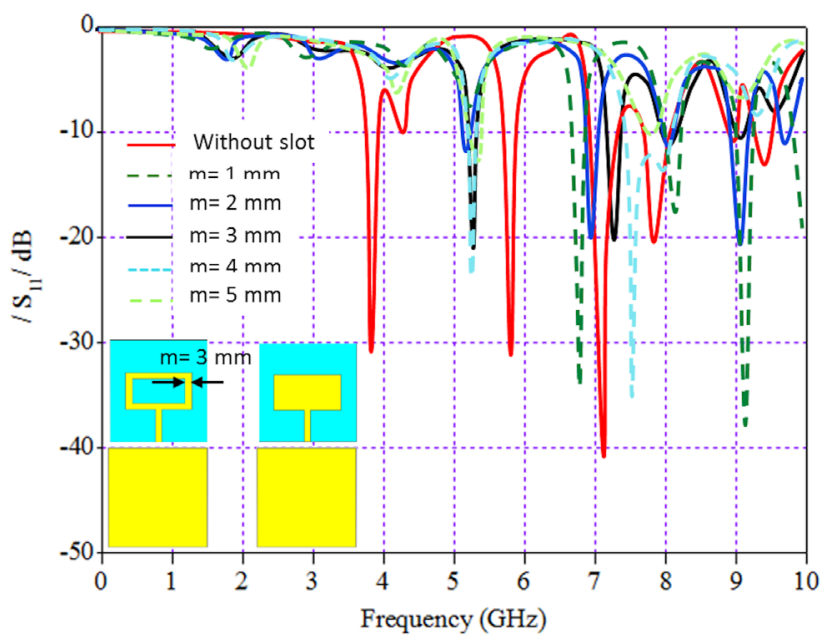

Fig. 2 Return loss of the proposed antenna with different values of $m$

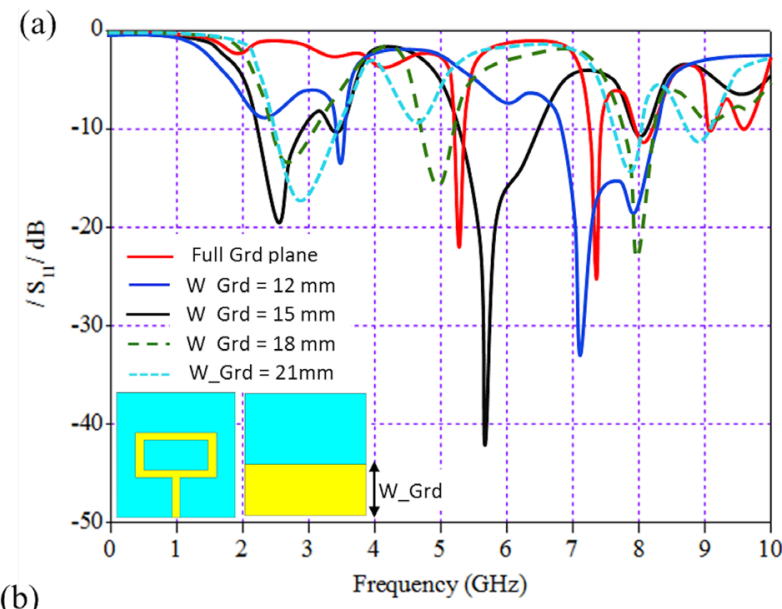

(b)

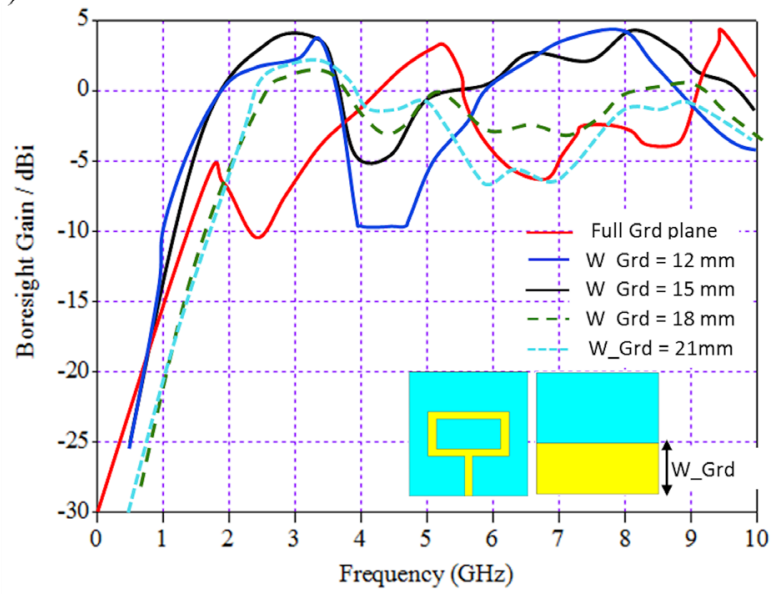

Fig. 3 Effects of $W_{-} G r d$ for the single patch on (a) $\left|S_{11}\right|$ spectra, and (b) Boresight gain

Next, to find the best feed line length of the proposed antenna, the authors studied the effect of the antenna feed length given by (L5) on the antenna performance. From Fig. 4 the simulation results indicated that the best impedance matching at the resonance frequency band at $5.8 \mathrm{GHz}$ 


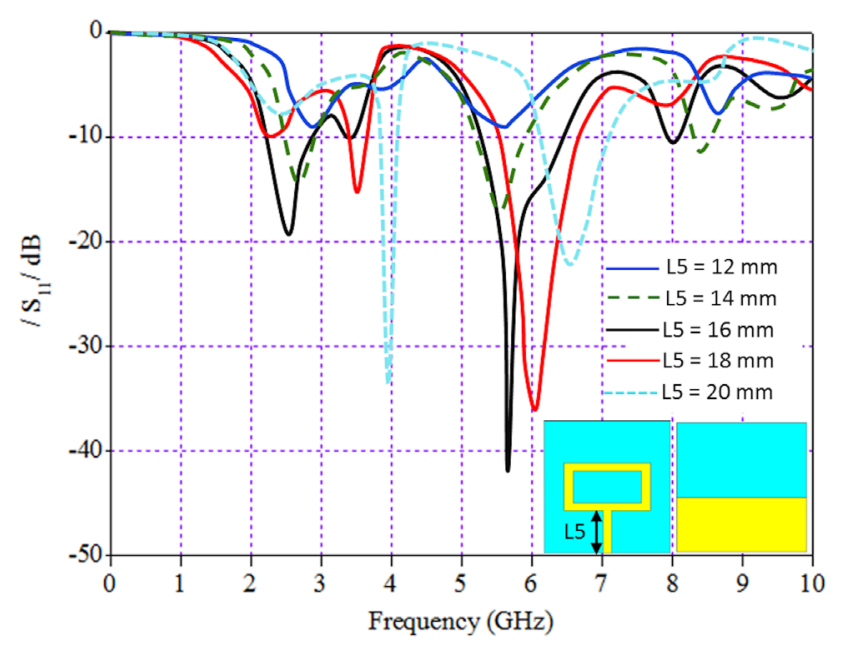

Fig. 4 The effects of $L 5$ changing on the $\left|S_{11}\right|$ spectra

when $L 5$ is equal to $16 \mathrm{~mm}$. Nevertheless, it is observed the impedance matching at first resonance mode at $2.45 \mathrm{GHz}$ is significantly affected in comparison to the second mode at $5.8 \mathrm{GHz}$. Such observation is attributed to the tangential surface current motion is relatively equal to the free space velocity on the slotted patch at $2.45 \mathrm{GHz}$. However, at $5.8 \mathrm{GHz}$ the current motion becomes much slower than the free space velocity that indeed provides less effect on the matching impedance [10].

A further investigation in this study is included to realize the effect of the antenna feed width as given by $(g)$. It is indicated from the simulated results; the proposed antenna is significantly affected by changing $g$ as shown in Fig. 5. The best matching spectra is achieved when set the $g$ to $3 \mathrm{~mm}$ as indicated in Fig. 5 .

\subsection{Antenna array}

The antenna array design with EBG structure is investigated in this section. The proposed antenna array consisting of two slotted rectangular patch antennas built on the low cost FR-4 substrate. Each patch is fed by a $50 \Omega$ microstrip transmission line, $3 \mathrm{~mm}$ in width, positioned on top of the substrate and backed by the partial ground plane through an (SubMiniature version A) SMA port as seen in Fig. 6.

The antenna array dimensions are $95 \times 50 \times 1.6 \mathrm{~mm}^{3}$. The proposed EBG structure dimensions are $47 \times 2.5 \mathrm{~mm}^{2}$. The EBG structure is constructed from 24 slots. The geometrical details of the proposed antenna array and the EBG structure are listed in Table 2.

Now, a comprehensive parametric study is carry out to investigate the optimal antenna array dimensions with respect to the optimal $\left|S_{11}\right|,\left|S_{21}\right|$, and the boresight gain pattern. The parametric study is started with

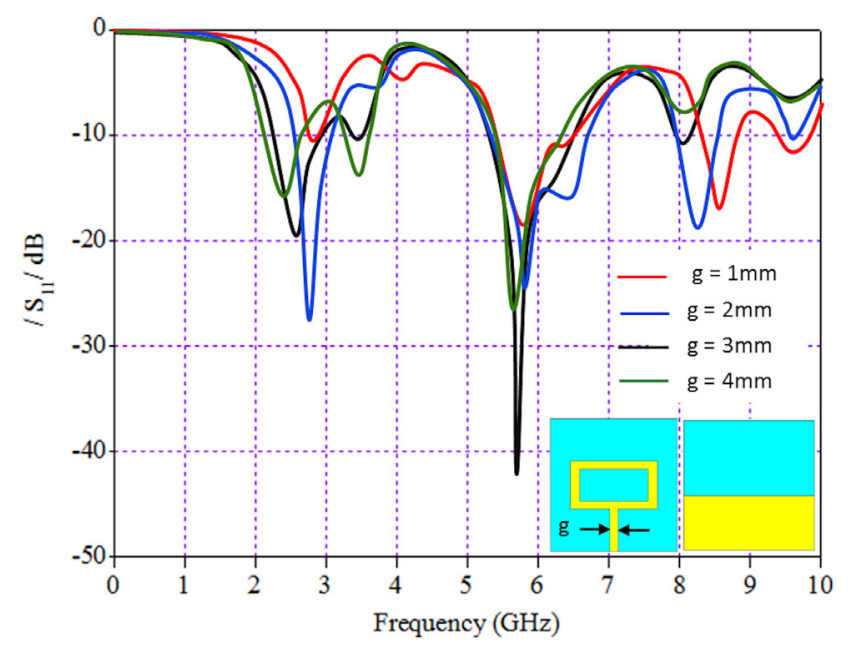

Fig. 5 Effects of $g$ for single patch on $\left|S_{1 \mid}\right|$ spectra

(a)

(b)

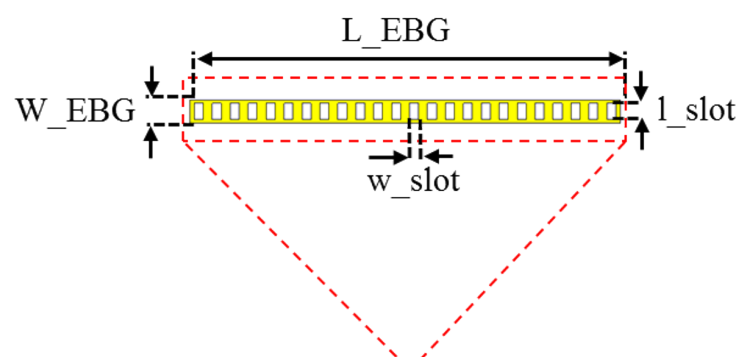

(c)
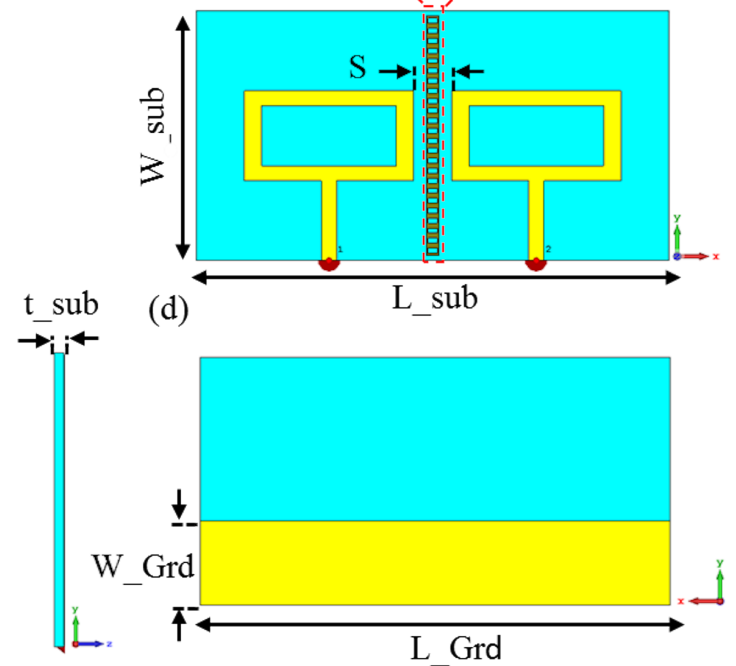

Fig. 6 The antenna geometry details; (a) front view of EBG structure (b) front view of the microstrip antenna and the EBG structure positioned between the two slotted microstrip patch antennas, (c) side view and (d) back view of the microstrip antenna

Table 2 The proposed antenna array dimensions and EBG structure

\begin{tabular}{lccc}
\hline Parameter & Dimension & Parameter & Dimension $(\mathrm{mm})$ \\
\hline$L_{-}$sub & 95 & $W_{-} E B G$ & 2.5 \\
$W_{-}$sub & 50 & $w_{-} s l o t$ & 1 \\
$L_{-}$Grd & 95 & $l_{-}$slot & 1.8 \\
$W_{-}$Grd & 15 & $S$ & 7.6 \\
$L_{-} E B G$ & 47 & $t_{-}$sub & 1.6 \\
\hline
\end{tabular}


antenna array design based full and partial ground plane. Then, a comparison between the achieved results from the two cases is presented in Fig. 7. From the presented results in Fig. 7, it is found the proposed array shows better performance when backed with the partial ground plane in comparison to the full ground plane structure. Such enhancement could be attributed to the reduction in the surface wave, skew waves, and motions on the ground plane surface [5]. Therefore, as far as the authors focused of the proposed antenna design to be suitable for WLAN and Wi-Fi applications, the antenna array design with the partial ground plane is considered for the next antenna design.

To overcome the space limitation in the MIMO antenna arrays, half wavelength $\left(\lambda_{0} / 2\right)$, with minimum mutual coupling, the authors conducted a further study on the separation distance $(S)$ between the radiating elements. Therefore, a parametric study is carried out to obtain the minimum distance with the minimum $\left|S_{21}\right|$. The study is started by changing $\mathrm{S}$ from $4.6 \mathrm{~mm}\left(\lambda_{0} / 26.5\right)$ up
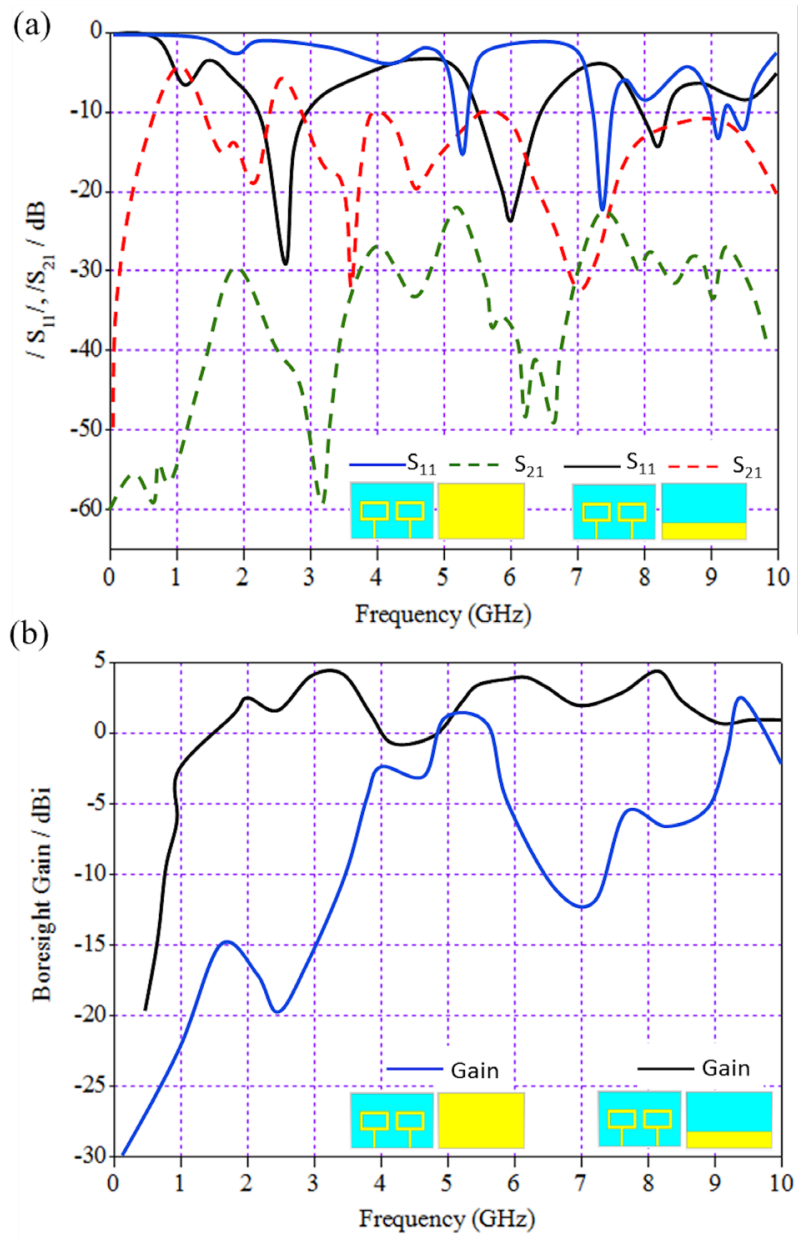

Fig. 7 Comparison between antenna array with full ground plane and partial ground plane in term of (a) $\left|S_{11}\right|,\left|S_{21}\right|$ and (b) Boresight gain to $19.6 \mathrm{~mm}\left(\lambda_{0} / 6.2\right)$ with a step of $3 \mathrm{~mm}$. The obtained $\left|S_{11}\right|$ and $\left|S_{21}\right|$ spectra for the proposed antenna array but without the EBG structure are presented in Fig. 8. It is observed from Fig. 8(b) that the antenna array with largest separation $19.6 \mathrm{~mm}$ has the lowest $\left|S_{21}\right|$; however, the $\left|S_{11}\right|$ is significantly degraded as seen in Fig. 8(a). This observation agrees with the achieved results in [12]. Therefore, the authors fixed $\mathrm{S}$ to $7.6 \mathrm{~mm}\left(\lambda_{0} / 16\right)$ to maintain the required $\left|S_{11}\right|$ and $\left|S_{21}\right|$ with minimum antenna array size.

Now, the introduction of the EBG structure is studied to realize the effect of that on the array size reduction. Therefore, a parametric study is adopted after introducing the EBG structure between the radiating elements. Such introduction may forbid the propagation of the surface waves over the desired operational frequency bands to improve the isolation between the radiating elements. The study is started by changing $S=4.6 \mathrm{~mm}$ up to $19.6 \mathrm{~mm}$ with a step of $3 \mathrm{~mm}$. From the simulated results in Fig. 9, it is indicated that the $\left|S_{21}\right|$ at $S=7.6 \mathrm{~mm}$ has been impro-ved to $-29 \mathrm{~dB}$ at
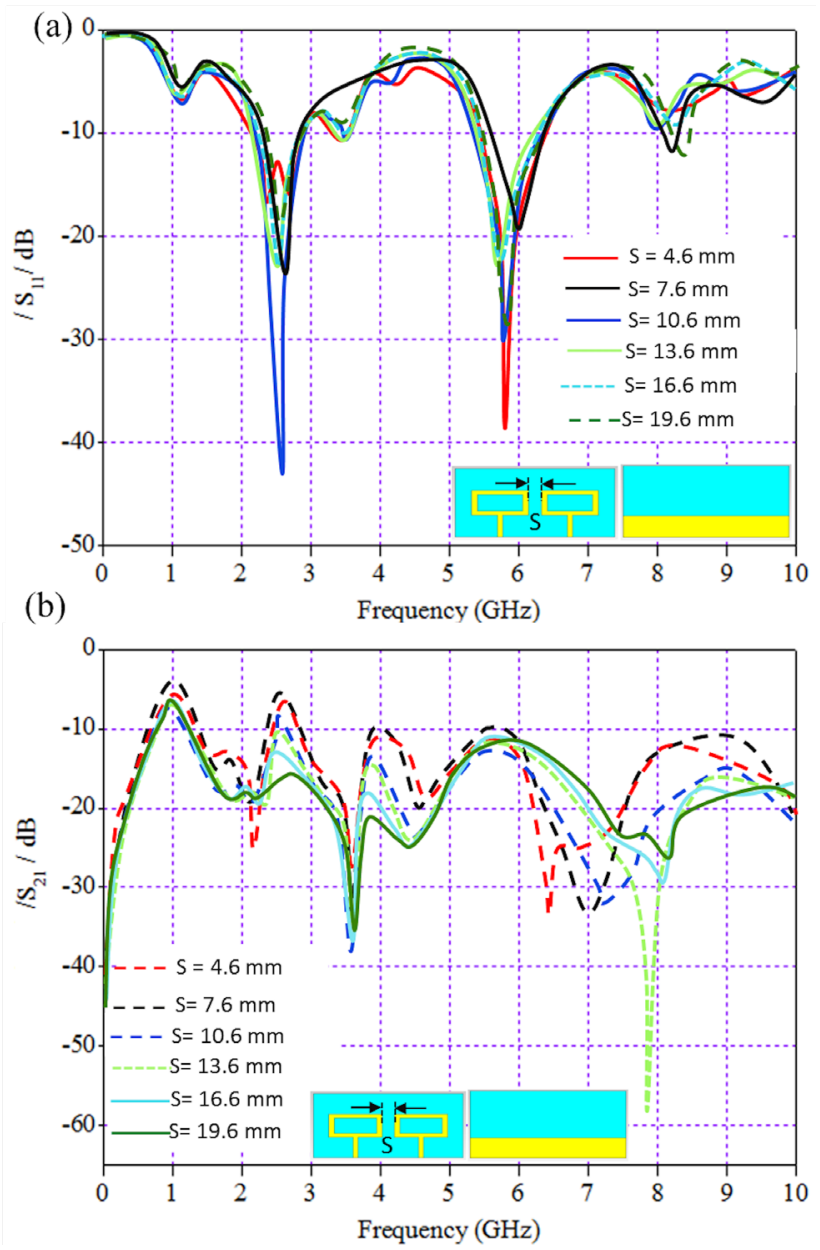

Fig. 8 The effect of $S$ between the antenna array without the EBG structure (a) $\left|S_{11}\right|$, and (b) $\left|S_{21}\right|$ 

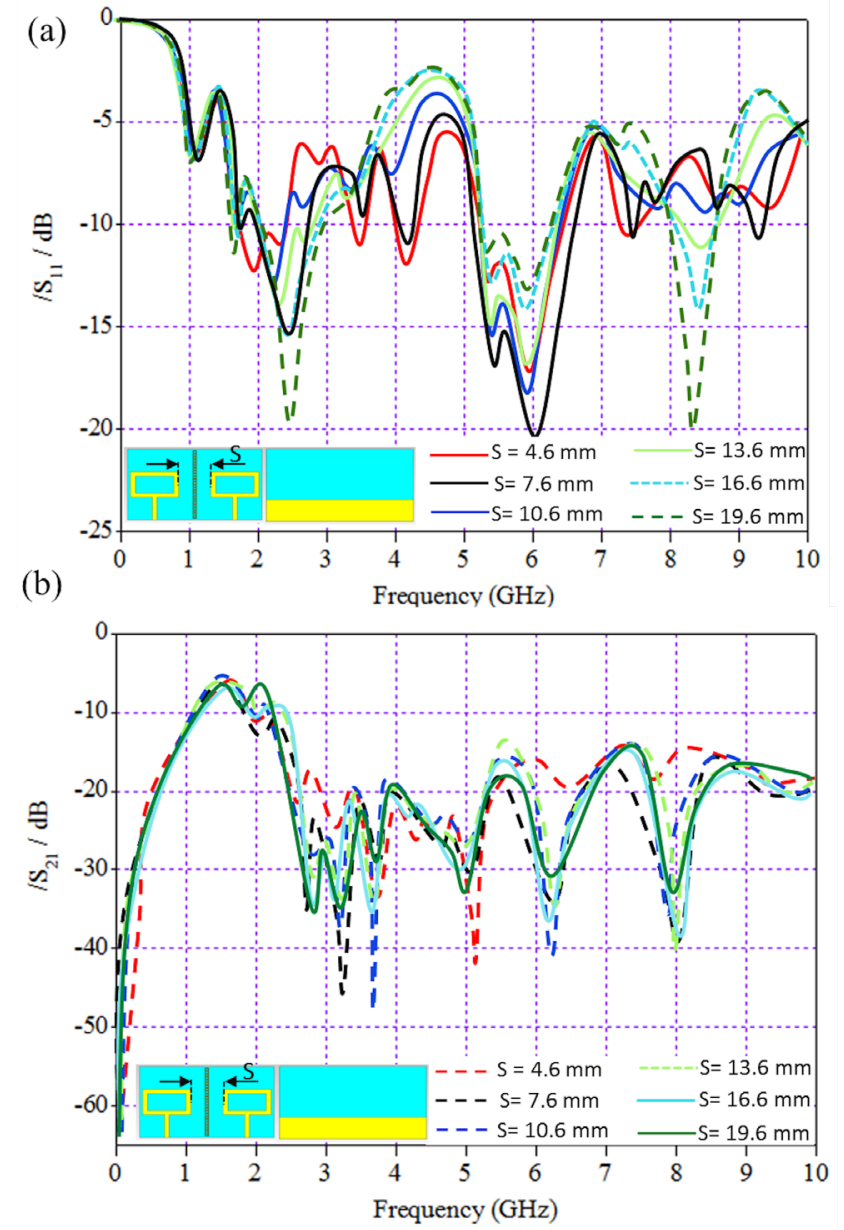

Fig. 9 The effect $S$ between the antenna array with the EBG structure (a) $\left|S_{11}\right|$ and (b) $\left|S_{21}\right|$

$2.45 \mathrm{GHz}$ and to $-25 \mathrm{~dB}$ at $5.8 \mathrm{GHz}$. This improvement is attributed to the EBG structure which has the capability to suppress the surface wave propagation and provide a mutual coupling reduction at the frequency band of interest [3].

In order to realize the optimal number of EBG unit cells between the radiating antenna elements, the authors studied the effect of the EBG unit cells number on the antenna performance. The study is started with one, three and five planar EBG unit cells. It is clear from Fig. 10, that the antenna array performance in terms of the $\left|S_{11}\right|$ and $\left|S_{21}\right|$ spectra are improved when the EBG unit cell number is increased from 1 to 5 .

Now, to investigate the influence of EBG structure on the antenna array performance, a compression between the proposed antenna array performance with and without EBG structure is studied. From the obtained $\left|S_{11}\right|$ and $\left|S_{21}\right|$ spectra which are indicated in Fig. 11; the proposed antenna array performance has been enhanced after introducing the EBG structure.

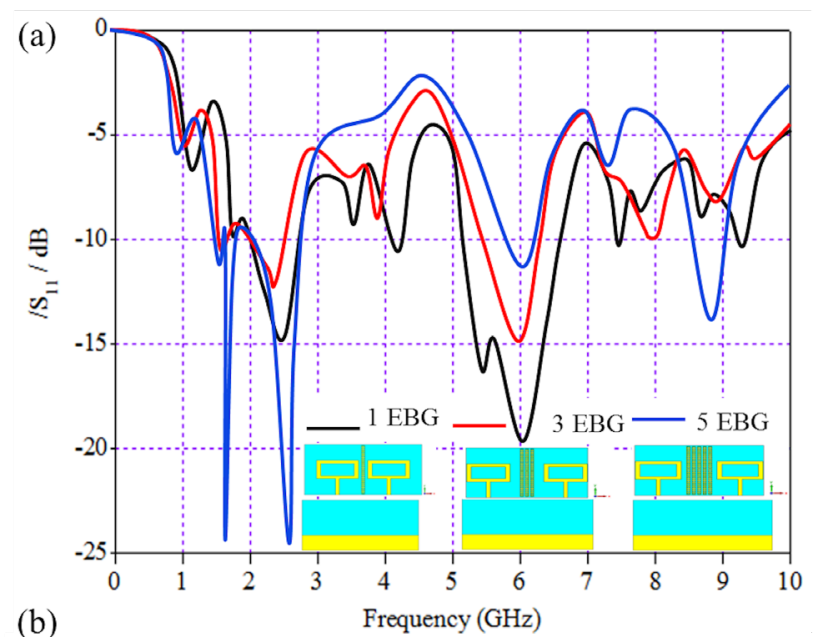

(b)

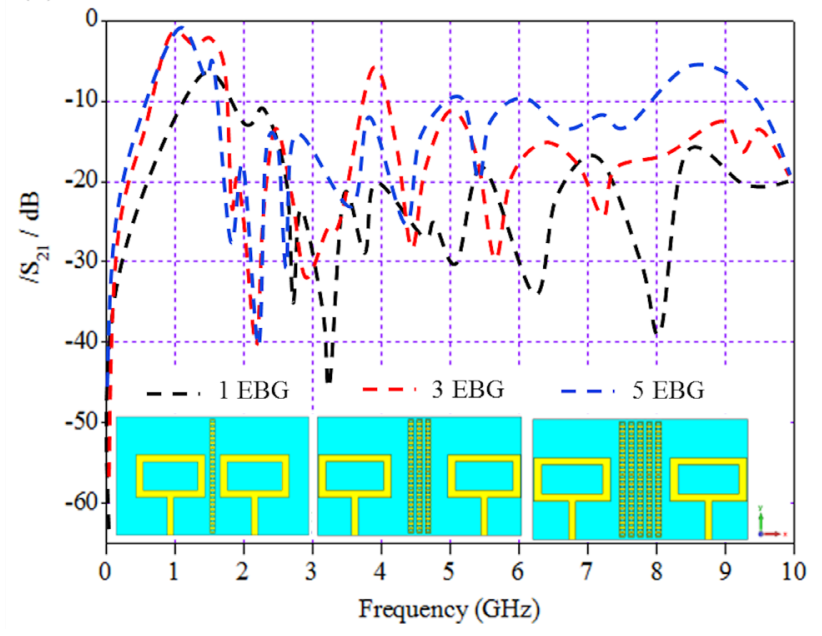

Fig. 10 The effect of number of EBG rows on the antenna array performance in term of (a) $\left|S_{11}\right|$ and (b) $\left|S_{21}\right|$

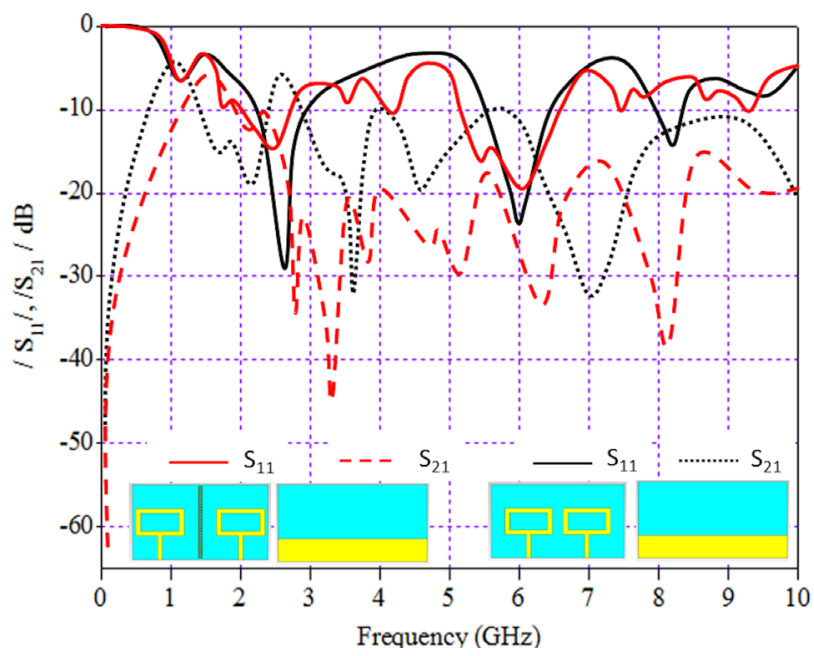

Fig. 11 Comparison of the antenna array performance with and without EBG structure in term of $\left|S_{11}\right|$ and $\left|S_{21}\right|$ spectra

In Table 3, the performance of the two cases is summarized to realize the effect of the EBG structure on the proposed antenna array performance. It is found that the EBG 
Table 3 The proposed antenna performance with and without EBG

\begin{tabular}{lcccc}
\hline \multirow{2}{*}{ Parameters } & \multicolumn{2}{c}{ Without EBG } & \multicolumn{2}{c}{ With EBG } \\
& $f_{1}$ & $f_{2}$ & $f_{1}$ & $f_{2}$ \\
\hline Frequency $(\mathrm{GHz})$ & 2.45 & 5.8 & 2.45 & 5.8 \\
$\left|S_{11}\right|(\mathrm{dB})$ & -25 & -20 & -15 & -18 \\
$\left|S_{21}\right|(\mathrm{dB})$ & -6 & -10 & -29 & -25 \\
Boresight gain (dBi) & 1.8 & 2.7 & 2.1 & 3.1 \\
$S(\mathrm{~mm})$ & 7.6 & 7.6 & 7.6 & 7.6 \\
\hline
\end{tabular}

(a)

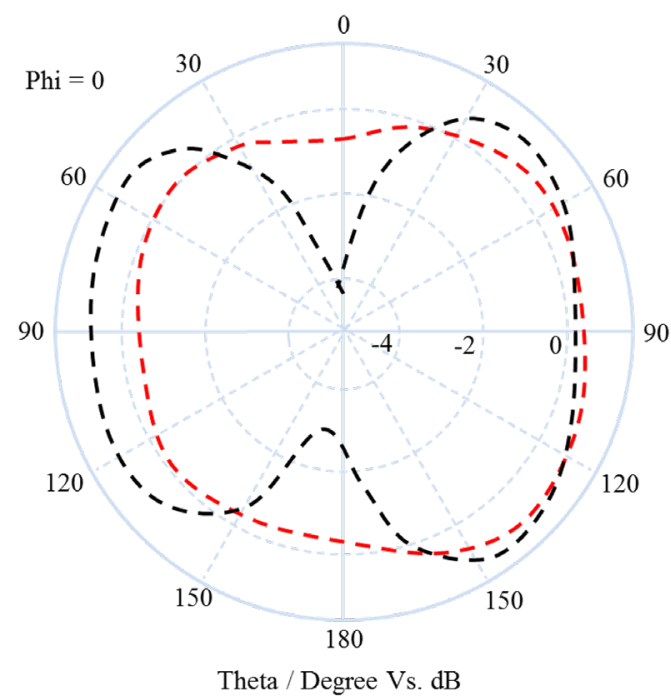

- - - E-field $(f=2.5 \mathrm{GHz})$ with $\mathrm{EBG}$

- - - E-field $(f=2.5 \mathrm{GHz})$ without EBG

H-plane/dBi

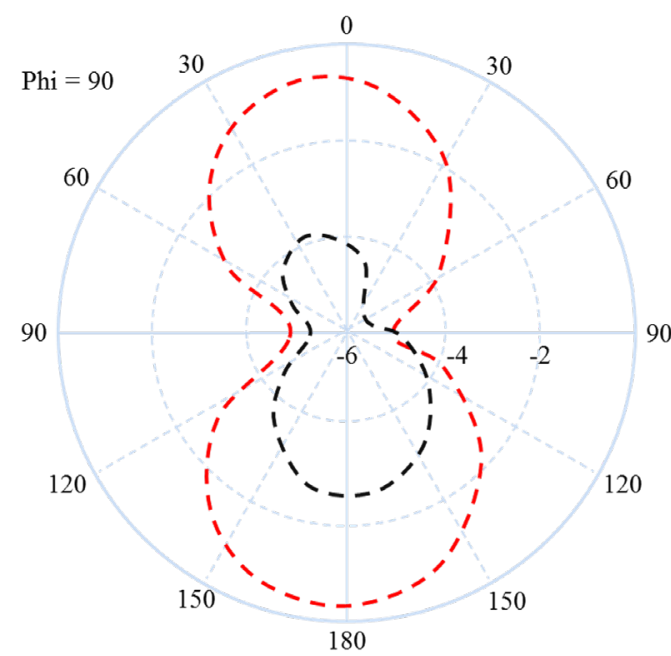

Theta / Degree Vs. dB

- - - H-field $(f=2.5 \mathrm{GHz})$ with $\mathrm{EBG}$

- - - H-field $(f=2.5 \mathrm{GHz})$ without EBG introduction has a significant effect on the $\left|S_{21}\right|$ reduction with minimum separation distance.

The antenna array radiation patterns with and without EBG at $2.45 \mathrm{GHz}$ and $5.8 \mathrm{GHz}$ respectively are shown in Fig. 12. From the simulated results the antenna array with EBG structure is improved in term of gain and radiation efficiency compared with conventional antenna array without EBG structure. In addition the directivity of antenna array has been improved after introducing the EBG structure. Next, the surface current distributions of the proposed

(b)

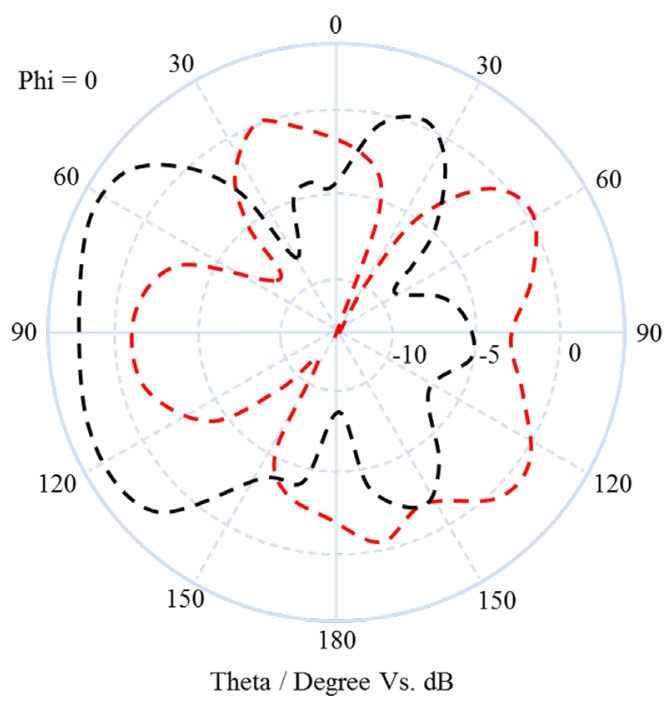

- - - E-field ( $f=5.8 \mathrm{GHz})$ with $\mathrm{EBG}$

- - - E-field $(f=5.8 \mathrm{GHz})$ without $\mathrm{EBG}$

H-plane/dBi

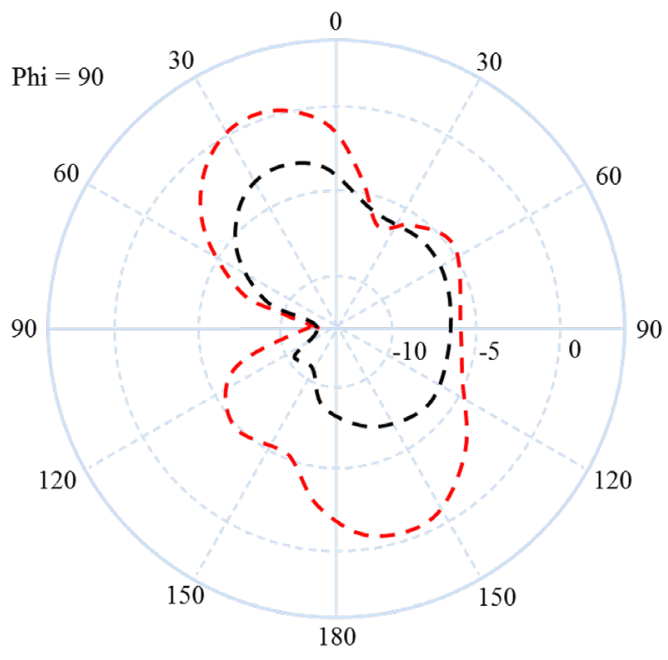

Theta / Degree Vs. dB

- - - H-field $(f=5.8 \mathrm{GHz})$ with EBG

- - - H-field $(f=5.8 \mathrm{GHz})$ without EBG

Fig. 12 The simulated far-field radiation patterns in the E-plane and H-plane of antenna array with and without EBG at frequency 
(a)

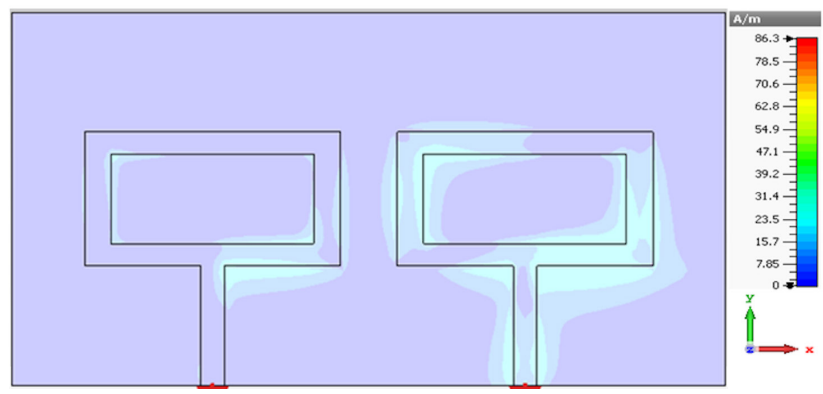

(b)

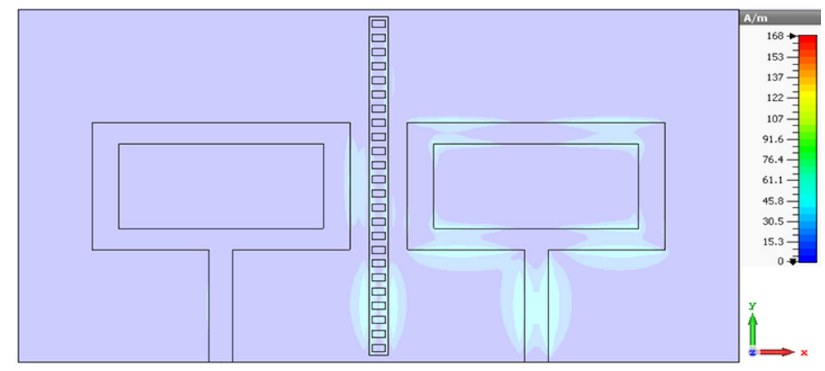

Fig. 13 Surface current distributions of two slotted microstrip patch antenna array (a) without EBG and (b) with EBG at frequency 2.45 GHz

antenna array with and without EBG structure are presented in Fig. 13. It is worth to mention that by placing EBG structure in between the antenna array elements the surface current is mainly distributed along the edges of the EBG structure. The proposed EBG structure has the ability to forbid the propagation of surface waves afterward, to provide an enhancement of the mutual coupling of antenna array.

\section{Folded antenna geometry}

In this section, we specify the effect of bending antenna array before and after introducing the EBG structure on the antenna performance, a numerical simulation using CST MW is presented. The antenna array is folded on a cylindrical substrate with inner radius; height and thickness are equal to $22 \mathrm{~mm}, 50 \mathrm{~mm}$ and $1.6 \mathrm{~mm}$ respectively as shown in Fig. 14.

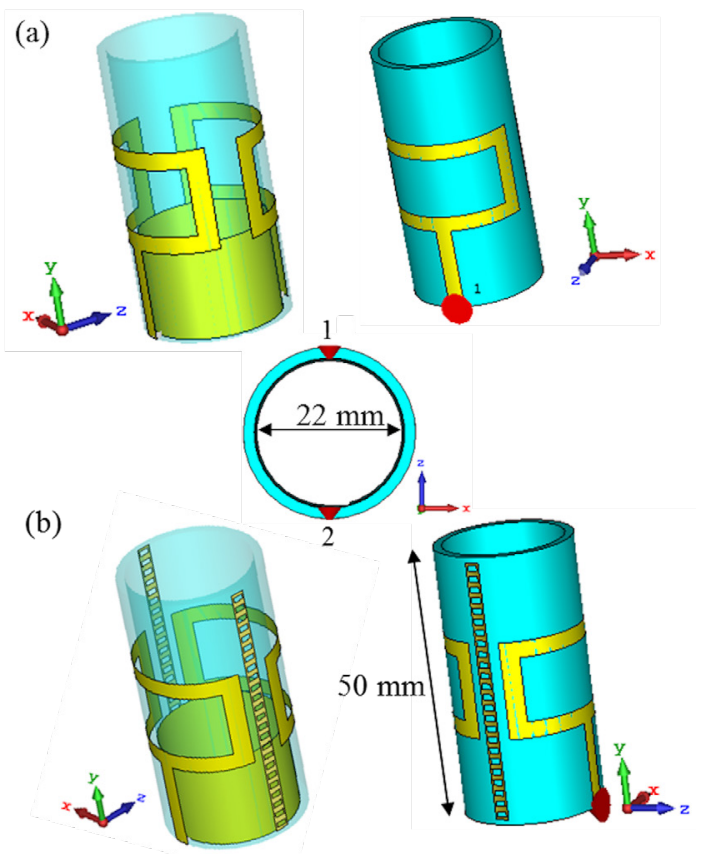

Fig. 14 The geometrical details of folded two slotted rectangular microstrip patch antenna array (a) without EBG and (b) with EBG
The performance of antenna array in term of $\left|S_{11}\right|$, and $\left|S_{21}\right|$ spectra for the planar and folded antenna array without EBG structure is presented in Fig 15. The simulated results exhibit a significant effect on the magnitude of the $\left|S_{11}\right|$ and the operating frequencies when the antenna array is bent. The desired operational bands and the resonant frequencies are shifted toward the lowest frequencies with poor impedance matching for the folded antenna arrays as shown in Fig 15.

A further investigation included comparison between the planar and folded antenna array with EBG structure is studied in this section. The antenna performance in term of $\left|S_{11}\right|$, and $\left|S_{21}\right|$ spectra for the planar and folded antenna array is presented in Fig. 16. The simulation shows that bending the antenna array exhibits a significant effect on the magnitude of the $\left|S_{11}\right|$, on the resonant frequencies and the mutual coupling.

Next, the authors investigated the influence of the EBG structure for the folded antenna array as indicated in Fig. 17. It is found that the folded antenna array with

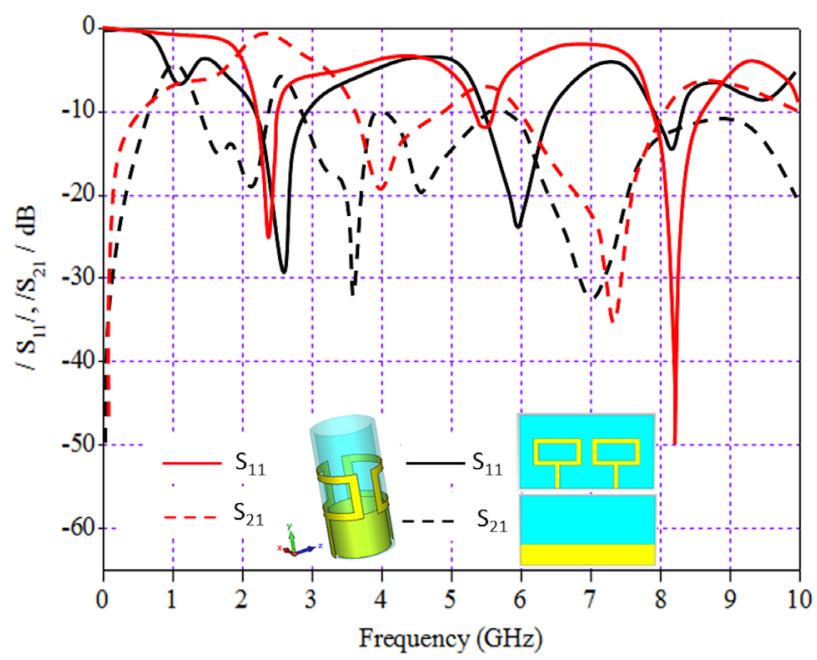

Fig. 15 Comparison of $\left|S_{11}\right|$ and $\left|S_{21}\right|$ of the antenna based on planar and folded antenna array without EBG 
EBG has better performance than the antenna array without EBG structure in terms of $\left|S_{11}\right|$, and $\left|S_{21}\right|$ too.

The $3 \mathrm{D}$ radiation pattern of the folded antenna array at $2.45 \mathrm{GHz}$ with and without EBG structure is illustrated in Fig. 18. The radiation of the proposed folded antenna array with EBG structure is an end-fire radiator. The radiation patterns are affected by introducing the EBG structure comparison with conventional folded antenna array without EBG. An improvement in antenna gain has been achieved from $1.6 \mathrm{dBi}$ to $2.45 \mathrm{dBi}$ after introducing the EBG between the radiating antenna elements. In addition, the directivity and radiation efficiency of the folded antenna array has been improved after introduced the EBG structure as indicated in Fig. 18.

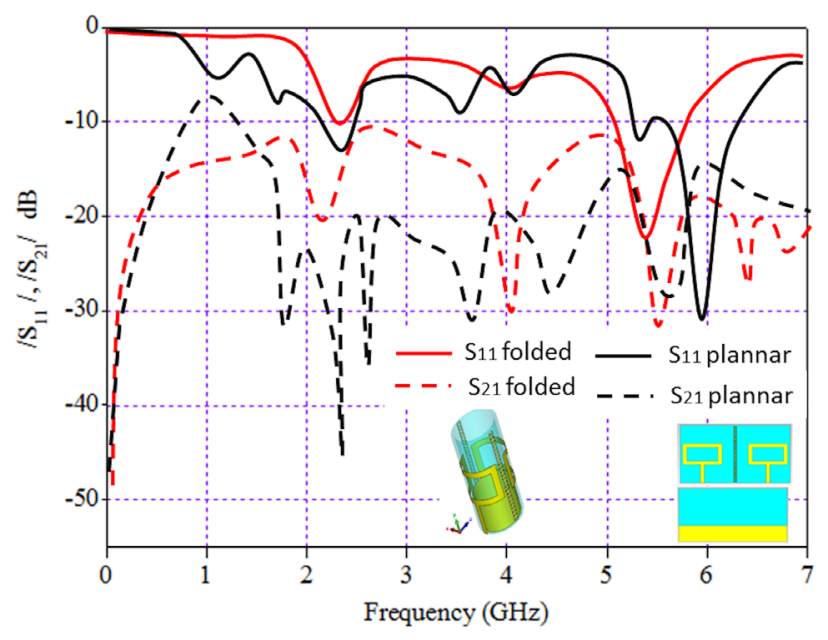

Fig. 16 Comparison $\left|S_{11}\right|$, and $\left|S_{21}\right|$ of antenna based on planar and folded antenna array with EBG
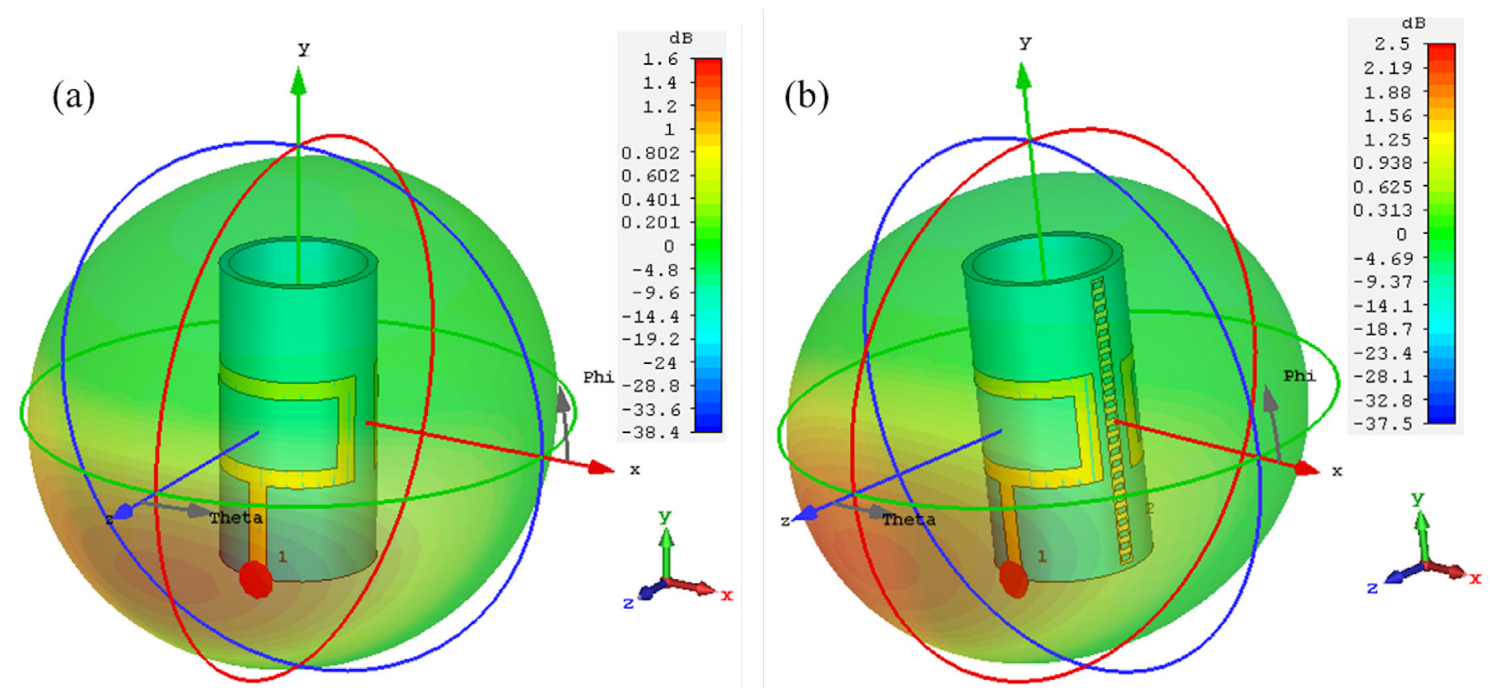

Fig. 18 Radiation patterns of the proposed folded antenna array (a) without and (b) with EBG structure

\section{Envelope Correlation Coefficient}

In this section, the Envelope Correlation Coefficient (ECC) using CST MW formulation has been investigated for diversity applications with two port antennas. ECC is considering one of the important parameter in order to insure that the MIMO antenna can work independently with others. The value of ECC in MIMO antenna should be as low as possible which is evidence that minimum cross talk can be observed during simultaneous operation of the two antenna ports. Fig. 19 shows the simulated ECC before and after introducing the EBG structure. From the simulated results an excellent ECC is achieved after introducing the EBG structure between the antenna elements. The proposed EBG structure is reduces the ECC from 0.001 to 0.0005 for the first frequency band and from

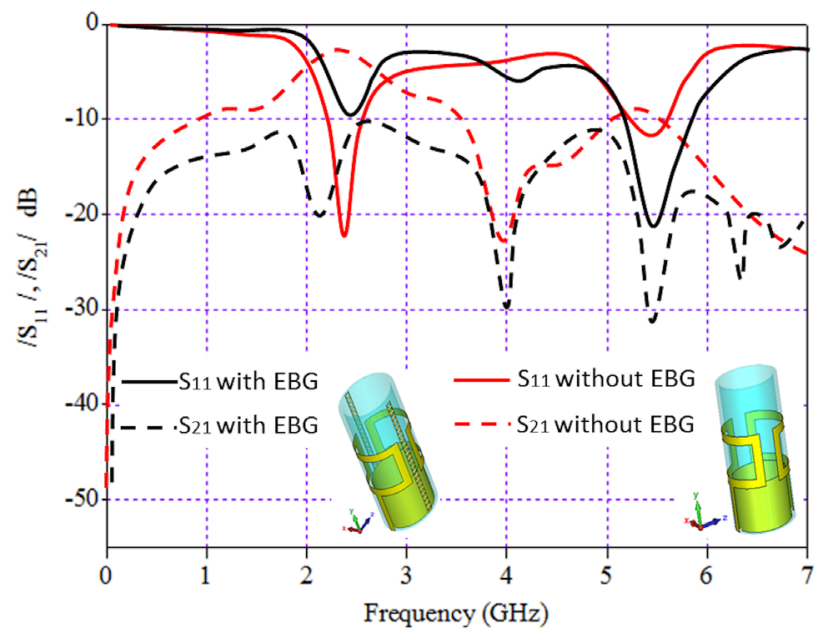

Fig. 17 Comparison $\left|S_{11}\right|$ and $\left|S_{21}\right|$ of antenna based on folded antenna array with and without EBG structure 
Table 4 Comparison between proposed antenna and recent works

\begin{tabular}{|c|c|c|c|c|c|c|c|}
\hline Reference & Method & Dimensions $/ \mathrm{mm}^{2}$ & Bands & Frequency/ GHz & Profile & Max. Isolation/ dB & Separation Distance \\
\hline [5] & SRR & $0.22 \lambda_{0} \times 0.28 \lambda_{0}$ & Single & 2.25 & Cylinder & -30 & $0.035 \lambda_{0}$ \\
\hline$[6]$ & BCSRR & $0.22 \lambda_{0} \times 0.29 \lambda_{0}$ & Single & 4.42 & Cylinder & -15 & $0.09 \lambda_{0}$ \\
\hline [7] & EBG & $0.24 \lambda_{0} \times 0.4 \lambda_{0}$ & Two & $2.161,9.433$ & Planar & $-19,-30.1$ & $0.3 \lambda_{0}$ \\
\hline [9] & MTM & $0.71 \lambda_{0} \times 0.85 \lambda_{0}$ & Single & 5.8 & Planar & -24.5 & $0.135 \lambda_{0}$ \\
\hline [10] & UC EBG & $0.34 \lambda_{0} \times 0.87 \lambda_{0}$ & Single & 5.8 & Planar & -20.3 & $0.14 \lambda_{0}$ \\
\hline [11] & EBG & $0.64 \lambda_{0} \times 1.23 \lambda_{0}$ & Single & 5.4 & Planar & -20 & $0.385 \lambda_{0}$ \\
\hline$[12]$ & Patch & $2.26 \lambda_{0} \times 1.04 \lambda_{0}$ & Single & 6.8 & Planar & -33 & $0.45 \lambda_{0}$ \\
\hline [13] & Slots & $1.86 \lambda_{0} \times 0.8 \lambda_{0}$ & Three & $9,15,19$ & Planar & -26 & $0.37 \lambda_{0}$ \\
\hline [14] & EBG & $1.31 \lambda_{0} \times 0.77 \lambda_{0}$ & Single & 5.8 & Planar & -43 & $0.36 \lambda_{0}$ \\
\hline [15] & SRR & $0.77 \lambda_{0} \times 0.5 \lambda_{0}$ & Single & 5.8 & Planar & -27 & $0.019 \lambda_{0}$ \\
\hline [16] & UC-EBG & $1.5 \lambda_{0} \times 1.5 \lambda_{0}$ & Single & 5.75 & Planar & -31 & $0.5 \lambda_{0}$ \\
\hline [17] & 3D MTM & $0.48 \lambda_{0} \times 0.48 \lambda_{0}$ & Single & 2.4 & Planar & -35 & $0.13 \lambda_{0}$ \\
\hline [18] & MTM-DS & $2.24 \lambda_{0} \times 0.883 \lambda_{0}$ & Single & $9.76,10.24$ & Planar & -57 & $0.66 \lambda_{0}$ \\
\hline This work & EBG & $0.77 \lambda_{0} \times 0.4 \lambda_{0}$ & Two & $2.45,5.8$ & $\begin{array}{c}\text { Planar and } \\
\text { Cylinder }\end{array}$ & $-29,-25$ & $0.0625 \lambda_{0}$ \\
\hline
\end{tabular}

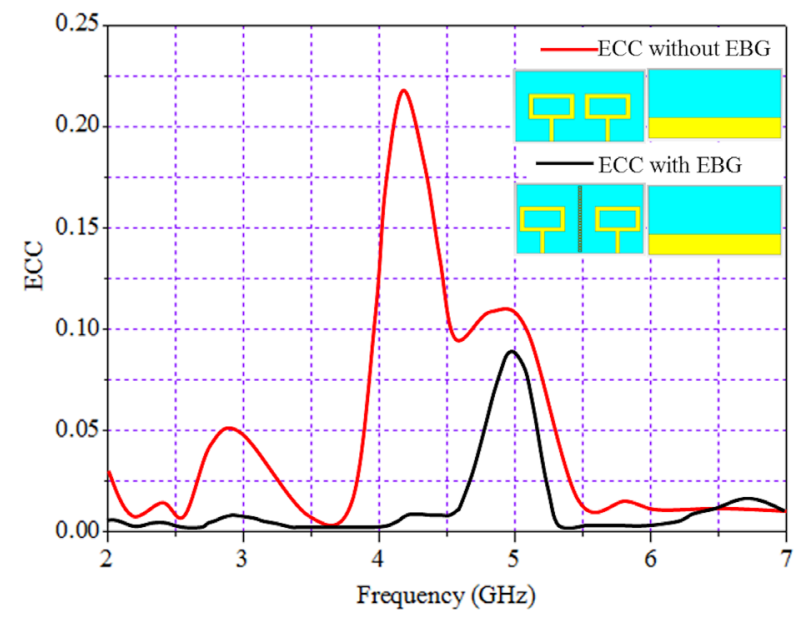

Fig. 19 Envelope correlation coefficient of the MIMO before and after EBG structure

0.001 to 0.0006 for the second frequency band which is proves that the two adjacent antennas are irrelevant as shown in Fig. 19. This low value of the ECC is evidence of less cross talk during simultaneous usage of both the ports which is achieved after introducing the EBG structure. From the simulated S-parameters, ECC can be calculated by using the formula described in Eq. (1) [14].

$\rho_{e}=\frac{\left|S_{11} * S_{12}+S_{21} * S_{22}\right|^{2}}{\left(1-\left(\left|S_{11}\right|^{2}+\left|S_{21}\right|^{2}\right)\right)\left(1-\left(\left|S_{22}\right|^{2}+\left|S_{12}\right|^{2}\right)\right)}$.

After validating the antenna performance numerically an EBG structure is invoked to improve the antenna array performance in terms of $\left|S_{11}\right|$ and mutual coupling. A significant enhancement is investigated after introducing the EBG structure compacted with conventional slotted antenna array. A comparison among the reported antennas and this study is summarized in Table 4, in term of antenna dimensions, metamatrials type, number of the operating band, separation distance, and the maximum isolation between the antenna elements. From Table 4, it is proven that compared to all published results, the proposed antenna array with EBG structure exhibits relatively excellent isolation with respect to the antenna array in comparison to other published results [5-18].

\section{Conclusions}

In this paper, a novel EBG structure is proposed between two antenna elements to reduce the mutual coupling for the MIMO antenna systems. A parametric study is conducted to investigate the antenna array performance to utilize the optimal dimensions that satisfy the requirements for WLAN and Wi-Fi applications. The separation distance between the proposed antenna elements is found about $\lambda_{0} / 16$ with low mutual coupling of $-29 \mathrm{~dB}$ at $2.45 \mathrm{GHz}$ and $-25 \mathrm{~dB}$ at $5.8 \mathrm{GHz}$ cause of EBG introduction. The antenna array structure is folded on a cylindrical substrate to suit the wearable applications in MIMO systems. It is found that the folded antenna array shows $\left|S_{11}\right|$ about $-10 \mathrm{~dB}$ at $2.45 \mathrm{GHz}$ and -19 at $5.8 \mathrm{GHz}$. However, the $|\mathrm{S} 21|$ is found about $-18 \mathrm{~dB}$ at $2.45 \mathrm{GHz}$ and $-25 \mathrm{~dB}$ at $5.8 \mathrm{GHz}$. Finally, it is concluded that the proposed antenna array mitigate the performance enhancements even after folding on a cylindrical substrate. 


\section{Acknowledgement}

The research reported in this paper was supported by the BME- Artificial Intelligence FIKP grant of EMMI (BME FIKP-MI/SC). The author Yahiea Al Naiemy would like

\section{References}

[1] Yablonovitch, E. "Inhibited Spontaneous Emission in SolidState Physics and Electronics", Physical Review Letters, 58(20), pp. 2059-2062, 1987.

https://doi.org/10.1103/PhysRevLett.58.2059

[2] John, S. "Strong localization of photons in certain disordered dielectric superlattices", Physical Review Letters, 58(23), pp. 2486-2489, 1987.

https://doi.org/10.1103/PhysRevLett.58.2486

[3] Alnaiemy, Y., Nagy, L. "Design and analysis of Ultra-Wide Band (UWB) antennas based on metamaterial", In: 2018 11th International Symposium on Communication Systems, Networks and Digital Signal Processing (CSNDSP), Budapest, Hungary, 2018, pp. 1-6.

https://doi.org/10.1109/CSNDSP.2018.8471835

[4] Imran, A. I., Elwi, T. A. "A cylindrical wideband slotted patch antenna loaded with Frequency Selective Surface for MRI applications", Engineering Science and Technology, an International Journal, 20(3), pp. 990-996, 2017. https://doi.org/10.1016/j.jestch.2017.04.001

[5] Elwi, T. A. "A Miniaturized Folded Antenna Array for MIMO Applications", Wireless Personal Coomunications, 98(2), pp. 1871$1883,2018$.

https://doi.org/10.1007/s11277-017-4950-4

[6] Elwi, T. A., Abbas, Z., Noori, M., Al-Naiemy, Y., Salih, E. Y., Hamed, M. M. "Conformal Antenna Array for MIMO Applications", Journal of Electromagnetic Analysis and Applications, 6(4), pp. 43-50, 2014.

https://doi.org/10.4236/jemaa.2014.64007

[7] Ahmed, M. I., Abdallah, E. A., El-Hennawy, H. M. S. "Novel Wearable Eagle Shape Microstrip Antenna Array with Mutual Coupling Reduction", Progress in Electromagnetics Research B, 62 , pp. 87-103, 2015.

https://doi.org/10.2528/PIERB14120901

[8] Alnaiemy, Y., Elwi, T. A., Nagy, L. "Enhancing the Microstrip Antenna Gain Using a Novel EBG Lens Based on a Single Layer", In: 2018 11th International Symposium on Communication Systems, Networks Digital Signal Processing (CSNDSP), Budapest, Hungary, 2018, pp. 1-4. https://doi.org/10.1109/csndsp.2018.8471786

[9] Iqbal, A., Saraereh, O. A., Bouazizi, A., Basir, A. "MetamaterialBased Highly Isolated MIMO Antenna for Portable Wireless Applications", Electronics, 7(10), Article ID: 267, 2018. https://doi.org/10.3390/electronics7100267

[10] Kumar, N., Kommuri, U. K. "MIMO Antenna Mutual Coupling Reduction for WLAN Using Spiro Meander Line UC-EBG", Progress In Electromagnetics Research C, 80, pp. 65-77, 2018. https://doi.org/10.2528/PIERC17101601 to record his indebtedness to Tempus Public Foundation Stipendium Hungaricum program and University of Diyala - Iraq for their support for his PhD scholarship.

[11] Naser-Moghadasi, M., Ahmadian, R., Mansouri, Z., Zarrabi, F. B. Rahimi, M. "Compact EBG Structures for Reduction of Mutual Coupling in Patch Antenna MIMO Arrays", Progress in Electromagnetic Research C, 53, pp. 145-154, 2014. https://doi.org/10.2528/PIERC14081603

[12] Yang, F., Rahmat-Samii, Y. "Microstrip antennas integrated with electromagnetic band-gap (EBG) structures: a low mutual coupling design for array applications", IEEE Transactions on Antennas and Propagation, 51(10), pp. 2936-2946, 2003. https://doi.org/10.1109/TAP.2003.817983

[13] Alibakhshikenari, M., Virdee, B. S., See, C. H., Abd-Alhameed, R., Falcone, F., Limiti, E. "Antenna Mutual Coupling Suppression Over Wideband Using Embedded Periphery Slot for Antenna Arrays", Electronics, 7, Article ID: 198, 2018. https://doi.org/10.20944/preprints201808.0359.v1

[14] Kaabal, A., El halaoui, M., Ahyoud, S., Asselman, A. "A Low Mutual Coupling Design for Array Microstrip Antennas Integrated with Electromagnetic Band-Gap Structures", Procedia Technology, 22, pp. 549-555, 2016

https://doi.org/10.1016/j.protcy.2016.01.115

[15] Wang, Z., Zhao, L., Cai, Y., Zheng, S., Yin, Y. "A Meta-Surface Antenna Array Decoupling (MAAD) Method for Mutual Coupling Reduction in a MIMO Antenna System", Scientific Reports, 8, Article ID: 3152, 2018.

https://doi.org/10.1038/s41598-018-21619-Z

[16] Farahani, H. S., Veysi, M., Kamyab, M., Tadjalli, A. "Mutual Coupling Reduction in Patch Antenna Arrays Using a UC-EBG Superstrate", IEEE Transactions on Antennas Wireless Propagation Letters, 9, pp. 57-59, 2010. https://doi.org/10.1109/LAWP.2010.2042565

[17] Yu, K., Li, Y., Liu, X. "Mutual Coupling Reduction of a MIMO Antenna Array Using 3-D Novel Meta-material Structures", ACES Journal, 33(7), pp. 758-463, 2018. [online] Available at: https:// www.semanticscholar.org/paper/Mutual-Coupling-Reduction-ofa-MIMO-Antenna-Array-Yu-Li/01e57e1d4d3ab2845485e1694b52 7030c1c19a55 [Accessed: 15 January 2019]

[18] Alibakhshikenari, M., Virdee, B. S., Shukla, P., See, C. H., AbdAlhameed, R., Khalily, M., Falcone, F., Limiti, E. "Interaction Between Closely Packed Array Antenna Elements Using MetaSurface for Applications Such as MIMO Systems and Synthetic Aperture Radars", Radio Science, 53(11), pp. 1368-1381, 2018 https://doi.org/10.1029/2018RS006533

[19] Dassault Systèmes "CST Microwave Studio", [computer program] Available at: http://www.cst.com [Accessed: 11 January 2019] 